\title{
What Do Social Workers Think About Unaccompanied Foreign Minors' Family Fostering in Italy
}

\author{
Anna D'Andrea ${ }^{a}$
}

\begin{abstract}
In Italy, the unaccompanied foreign minors are a growing and heterogeneous group with ever changing origins, trajectories, and features. In November 2015, they were 10,952. This research focuses on their foster care and examines the point of view of social workers that have theoretical competences and fieldwork. The main objective of this paper is to present operational recommendations concerning the definition and organization of this instrument, starting from social workers' direct experiences. Main results: A friendly familiar setting is useful to overcome loneliness and social isolation coming from a new and unknown reality during adolescence and permit a better social, school, and professional integration for the minor compared with residential care. For a successful outcome, the strengths consist in: The young migrant must not have behavioral nor psychiatric disorders and must be willing to integrate himself into a new family, recognize adult authority and share his life plan with family's adults; training all foster families included omo-cultural ones; the birth family involvement in the foster care's project. The ascertained criticalities concern on the low number of available families, the lack of standard operating procedures, guidelines, research, and literature on the topic.
\end{abstract}

\section{Keywords}

Unaccompanied foreign minors, foster placement, social services

This research is intended to explore the legal instrument of family foster care for unaccompanied foreign minors. The main aim of this paper is to provide methodological recommendations concerning the definition and organization of this instrument, starting from direct experiences of social workers working with unaccompanied foreign minors.

The specific objectives can be resumed as follows:

(1) To understand deeply the spreading of this instrument and its operational procedures and guidelines at the national and local level;

(2) To evaluate the experience of the custody as an useful opportunity for young unaccompanied migrants and as a possible practical response to their needs;
(3) To find the main evaluation indicators of minors and foster families in order to improve social services' work.

After an in-depth bibliographic examination, three exploratory interviews were conducted with specialized social workers.

These interviews have been involved professionals working in social service focused on unaccompanied

aUniversità Ca' Foscari di Venezia, Italy

\section{Correspondent Author:}

Anna D’Andrea, Via Massa Carrara, 6, 40139, Bologna, Italy E-mail: 835086@stud.unive.it 
foreign minors' reception in Bologna; people interviewed prefer to stay anonymous.

Doctor Claudia Arnosti, author of Affido Senza Frontiere. L'affido Familiare Dell'adolescente Straniero non Accompagnato (2006) has been interviewed, too.

The analysis of the subject has allowed the comparison of the collected material and the coordination of the results.

\section{QUANTITATIVE DATA ON UNACCOMPANIED FOREIGN MINORS}

Ministry of Labour and Social Policy's data updated on November 30, 2015 indicates that unaccompanied foreign minors in Italy are 10,952 [Ministero del Lavoro e Delle Politiche Sociali (Ministry of Labour and Social Policy) 2015]. This figure can considerably change monthly, but it has been gradually growing during last year. The origins, the path, and the characteristics of this migrant flux change constantly (Salimbeni 2011: 19): We face a heterogeneous phenomenon which cannot be defined precisely and which cannot be circumscribed to the data collected.

Moreover, it is necessary to underline that minors asylum seekers having applied for international protection and EU (European Union) citizens are not considered in this category.

\section{RECEPTION AND PROTECTION OF UNACCOMPANIED FOREIGN MINORS}

As far as it concerns social policies and migrations' management, municipalities during last year have been playing a crucial role. Reception and protection actions realized by local authorities have proved to be an important pillar for improving unaccompanied foreign minors' condition, and this has been possible also thanks to inclusive projects. Foster placement of children has been representing one of the interventions experimented in some areas, it implies the reception of a teenager emigrated in Italy alone by an Italian or foreign family or individual.

Usually, the majority of these youngsters are hosted in residential communities; a minority of them are placed in foster care, an experimental instrument still not having national or regional procedures, since every municipality decides independently which protection intervention to choose for the minor.

Since relevant data on this phenomenon are not published, we need to obtain them from other researches.

According to the Final Report published by the Ministry of Labour and Social Policy, regarding the percentage of unaccompanied foreign minors out of the totality of foreign minors in family foster care up to December 31, 2011, it is possible to find out that only eight regions out of 21 have started family-based reception paths having on average $13 \%$ of unaccompanied minors hosted out of the totality of foreign youngsters in custody [Ministero del Lavoro $e$ Delle Politiche Sociali (Ministry of Labour and Social Policy) 2011: 27]. Regions involved are few, and some of them have scant numerical values.

Foreign minors living in Italy with their parents and being in custody because problems related to the natural family are $17 \%$ out of the total presence of adolescents and children in family foster care in the country [Ministero del Lavoro e Delle Politiche Sociali (Ministry of Labour and Social Policy) 2011: $11]$.

Other estimated data on fostering of unaccompanied foreign minors in Italy can be taken from Anci-Cittalia's Forth Report-I Minori Stranieri non Accompagnati in Italia published in 2011. Although these data are not referred to a specific year, the report underlines an age analysis: The majority of these minors are 16 years old (28.7\%) and 17 years old $(53.3 \%)$. As far as it concerns nationalities, minors in custody come from different countries but Senegalese minors (18.1\%) and Bengali minors (16.7\%) prevail. 
The report indicates the percentage of fostering per typology:

(1) Omo-cultural family foster care (families or individual having the same culture of the minor) is $63.5 \%$;

(2) Foster families or individuals having different nationalities from the minor's one are $23.4 \%$;

(3) Foster Italian families are $11.4 \%$.

\section{THE ACTORS IN THE INTERVENTION}

\section{The Minor}

At the national level, the legal condition of unaccompanied minors is defined by Article 1 Clause 2 of 535/1999 Ministerial Decree: "A minor who does not have Italian or other EU citizenship, has not applied for asylum and is, for any reason, within the territory of the State without care or representation by their parents or other adults who are legally responsible for them under existing Italian laws".

We are dealing with youngsters leaving their country and their family, alone, without adults, in the majority of cases because of conditions not depending from them: for example, family situation or extreme economical precariousness in the country of origin or lack of opportunities and perspectives for young people.

They are adolescents aged 15-17 years old who have to face a double challenge: They face not only the adolescence phase, but also their migrant path and the reality of the country of destination. Probably most of them have decided to leave because of their curiosity, desire of knowing and experimenting, typical of their age.

Even if for some of them, the willingness to leave their country of origin is strong, migration implicates the loss of the loved ones, loss of guarantees and identity; moreover, being alone, they do not have adults guiding them in their adaptation path. Adolescence and migration amplify difficulties of positive growth for the youngsters.

Cultural impact and cultural predominance in the new social context make foreign minor's identity formation process more demanding.

This minors experiment is called premature adultification. Family mandate concerning economic responsibilities, which motivates youngsters to leave the country in search of well-being and better opportunities, as well as the escape from wars and persecutions are symptoms of an adultification process, defined as an assuming of "age inappropriate social roles" (Di Nuzzo 2013: 38), a behaviour of premature responsibility. Because of the experiences and the education received, often these minors in their country of origin are considered as adults and are asked to be responsible for the economical conditions of their families.

Moreover, the migratory path represents a traumatic and painful experience for some minors, having high emotional impact: This experience itself is part of an adultification process, age inappropriate and revealing lacks and needs linked to their age.

Family foster care cannot be a solution for satisfying all unaccompanied foreign minors' needs (Arnosti and Milano 2006: 133). Some of these minors have the capacities to face critical situations characterizing the migrant path or the integration process in the country of destination; others do not have personal competences and resources, they are alone and without reference points.

For these reasons, it is necessary to verify whether it is needed and effective for the young person to live in a foster family, since this experience has to be helpful in the creation of a plan for his future and in building his personality. In some cases, this experience can cause critical issues and conflicts in the relationship between the adolescent and the family and in the minor himself, who needs a different intervention (Arnosti and Milano 2006: 123).

Literature points out some evaluation indicators useful to improve the scientific effectiveness of social services' work. 
It is essential that the minor accepts the idea of being included in a new family context and that he considers the foster care as an opportunity for himself. If the minor has developed "good emotional bonds" in the past (Arnosti and Milano 2006: 133) with relevant mentors, the family foster care will be well-accepted.

It is important that the young person recognizes adult authority and establishes a good relationship respecting everyone's role. Minor's willingness to share and to achieve his life plan in cooperation with the adult is necessary.

Family foster care has to be considered as an exchange (Arnosti and Milano 2006: 114), a relationship in which the family provide to the minor the help needed and the minor is concerned in an emotional and behavioural restitution.

The adolescent applying for custody should not have psychic or behavioural disturbances, aspects that the family itself will not be able to solve from a therapeutic point of view (Arnosti and Milano 2006: 133), and usually minors having previously lived in a residential community are chosen.

Minor's ability to stay in well-defined social context and to respect social rules, his ability to adapt, and his determination are important elements contributing to project's success.

\section{The Foster Family}

For foster care experience, families should have specific abilities facilitating helping process. Operational approach provides indicators supporting the service involved in the evaluation of the family. For example:

(1) Open-mindedness toward a different culture and the consideration of the encounter with others as an individual and collective enrichment;

(2) Listening abilities and communication capacities, especially with adolescents;

(3) The ability to re-organize family roles and personal expectations according to minor's needs and peculiarities. Change is an unavoidable element inside the family, it is a factor that has to be considered and accepted as necessary in minor's fostering;

(4) The capacity to accept an uncertain situation, because changes are long processes and the results of these processes cannot be expected or predicted (Arnosti and Milano 2006: 54);

(5) Family's willingness to care for a limited period an adolescent having already his life plan. Also in this case, time dimension is relevant, and it implies an approach of "starting and ending parenting functions" (Arnosti and Milano 2006: 29): It implies the consciousness that support, even the educational one, gave to the minor is a temporary help coherent with the contingent need. The minor has a family in his country of origin able to satisfy his needs, and its role has to be respected.

\section{METHODOLOGICAL PROCEDURE}

\section{Operational Procedure of the Social Services Involved}

Reception of unaccompanied foreign minors is coherent with the legislation on traditional family foster care (Law 149/2001): part-time, full-time, intra, and hetero family foster care. Fostering process partially reflects the procedures characterizing traditional fostering and social services are asked to carry out the same functions.

Minister of Labour and Social Policies underlines that a "specific planning taking into account the context, the actors and minor's migratory plan" [Ministero del Lavoro e Delle Politiche Sociali (Ministry of Labour and Social Policies) 2013: 56] has to be implemented. Nevertheless, it is possible to outline work phases that can be identified in every intervention (Arnosti and Milano 2006: 142).

Training social workers on the specific conditions of unaccompanied minors and on a necessary open-mindedness toward different cultures (Vari 2009: 56) is a precondition. Furthermore, it is important to 
promote family foster care and raise local community's awareness about it (Vari 2009: 56).

A first intervention phase is foreseen, consisting in collecting all relevant information about the minor and the foster family. During this phase, it is important to examine in depth all information on the minor, thanks to the professionals participating to the overall evaluation (for example, his psychologist, his educator, and his teacher).

During the second phase, social service activates the intervention and follows in the monitoring activity; foster family has to be supported in the transition from minor and reception idealization to the concrete experience. Both for the family and for the minor, fostering experience represents a critical changing moment: for this reason, both need to be supported to overcome this phase, by looking for a new harmony.

A last phase consists in supporting actions aimed at allowing the minor to have a good personal autonomy and effective social integration and allowing the foster family to re-organize itself in the detachment phase.

Social service should play a guiding role and should be a context where to express worries and expectations, and where the minor and the family exchange their views during the entire fostering process.

\section{The Objectives of Family Foster Care}

The main objectives of this instrument are the achievement of an effective autonomy and a good social integration. Achieving these objectives is the main advantage the minor can take, thanks to this experience.

As far as it concerns the achievement of emancipation, most of times, this is linked to the family mandate focused mainly on the search for a job that could allow to incomes for the birth family. The minor has to provide for his own and for his birth family, finding a way to pay the debt his parents incurred in order to pay his travel to Italy. Nevertheless, in the country of destination, the minor rarely finds a job, unless it is illegal, because of his age. Thus, the minor is directed to vocational trainings by the social services, which support him in finding a job necessary for staying on the Italian territory after his legal age (Gandini 2007: 82).

Regarding the second objective, it is necessary to underline that integration is never easy. Initially the minor arrives in an unknown country, with a different value system, different relational modes and family roles: In this context, it is complicated to use one's own resources and capabilities, most of times linked to the context of origin. When arrived in Italy, most of minors do not have the instruments to face complex, new, and unexpected situations. However, the family becomes a resource for minor's social integration, acting as a mediator between the minor and the local community.

\section{RESULTS}

The following remarks derive from the analysis of the specialized literature and from interviews made to experts working with unaccompanied foreign minors.

Compared with Italian minors' fostering, unaccompanied foreign minors' fostering has some peculiarities.

First of all, the birth family is not physically present; it lives in the country of origin, and for this reason, an intervention with the family is not foreseen. Although the birth family is not present, it remains an important reference point for the minor, through his stories, his memories, and his emotional experiences. Most of times, minors have telephone relationship with the birth families; in some cases, the birth family is involved in minor's decision-making and it has influences on his choices (Arnosti and Milano 2006: 138). For this reason, it is better to involve the birth family in the project.

The second difference between Italian and foreign 
minors' fostering is related to the different aims of these instruments. In the case of an Italian minor, the main aim of the action is the return of the minor to his birth family, but in case of unaccompanied foreign minor, the birth family does not have parenting deficiencies. Simply, the birth family is not present.

Another peculiarity is the duration of the intervention, which is short, coherently with the law foreseeing maximum two years of custody. Usually, these minors are welcomed in foster families when they are 16/17 years old and when they are over 18 , the custody comes to an end.

Moreover, commonly the adolescent phase is considered not to have positive results in custody processes, and social services' behaviour could lead us to think that they are oriented mainly to address adolescent unaccompanied foreign minors to residence communities instead of foster families.

Starting from this brief in-depth analysis, it is possible to deduce some critical issues that the author will shortly list.

\section{An Insufficient Regulatory Framework}

At national level, the regulatory framework is critical and complex: It does not support and guarantee the specific rights of unaccompanied minors.

\section{Lacking Operational Procedures and Guidelines on the Realization of the Unaccompanied Foreign Minors' Custody}

The documents that are recommended are Ministry of Labour and Social Policy's guidelines Linee di Indirizzo per L'affidamento Familiare (2013), whose smallest part is focused on operational procedures to be applied in unaccompanied foreign minors' custody and Anci-Cittalia's Forth Report titled I Minori Stranieri non Accompagnati in Italia (2012).

As far as it concerns policies focused on unaccompanied foreign minors, local practices reveal noteworthy relevance. However, some critical issues still remain: Local organizations do not collaborate with each other and the theoretical and practical knowledge on these issues is dispersed. Moreover, social workers who are responsible for the realization of individual projects directed to unaccompanied foreign minors do not have complete information about fostering system and operational procedures at a local level, they do not even have data concerning fostering results. It is difficult to understand, for example, the diffusion and impact of this instrument at a national level compared with other custodies, and which municipalities are involved in it.

It is necessary to underline that in some cases, unaccompanied minors' fostering is still an experimental project or it has been started few years ago, thus, it is difficult to demonstrate its efficacy and the results achieved.

\section{Insufficient Quantitative and Qualitative Data and Lacking Literature on This Theme}

At a national level, quantitative and qualitative analysis on the phenomenon, scientific bibliography, and literature focused on unaccompanied foreign minors' family foster care are very poor.

\section{Fostering as an Additional Option}

Family foster care is usually recognized as an option to be preferred to community custody, since the family environment is more appropriate to host a minor. However, most of youngsters are addressed to residential communities by the social services. This suggests that foster families do not have the necessary resources for supporting the foreign minor and that the minors, in some cases, do not have the characteristics necessary for a successful fostering. Thus, it is necessary to work in a complementary perspective between residential communities and family fostering.

As far as it concerns social integration, foster families have more resources instead of residential communities, since the family has a network of relationships, services, and knowledge in the local community. These factors facilitate a real integration 
of the youngster and offer concrete opportunities for him. This is a richness that residential communities and social workers could not have.

\section{Lack of Families Willing to Foster, in Particular Unaccompanied Minors}

It is necessary to underline that the major critical issue pointed out in the literature and from social services is the lack of subjects willing to foster adolescents. This attitude is linked to the risks that this intervention may entail for the family, whose equilibrium should be put to the test because of the presence of an adolescent not knowing the family norms. Family fostering has to be valued because of the benefits it entails and it has to be encouraged in the whole social community, but it needs specialized social workers focused on all the aspects characterising the process in all its phases.

\section{Differences Among Italian and Omo-Cultural Foster Families}

Despite every foster family or foster subject has good capacities, it is needed to highlight that Italian foster families have greater abilities in supporting the youngster in his integration path. In particular, the knowledge of the Italian language, a good network, different experiences, and opportunities are elements supporting the minor in having more interactions with the local community, enhancing a process of cultural approach. This capacity can be observed also in a foreign foster family well integrated in the local context: In this case, the family can support minor's social integration and minor's conservation of relationships and values linked to his cultural belonging.

Actually, Italian families fostering unaccompanied foreign minors are few, omo-cultural custody is preferred and in most cases, family fostering involves foreign families. This is linked to the fact that social services prefer to give the custody to minor's relatives living in Italy and to hold them responsible for him.

\section{The Complexity of Family Foster Care}

Family fostering is a demanding and burdensome instrument; it does not facilitate social services' work, since it implies the involvement of all the subjects linked to the minor. The success of the intervention depends on different factors, for example, the resources available, the characteristics of the users, and social workers' capacities of monitoring relationships, expectations, difficulties, and emotions of the subjects involved.

The complexity of this instrument is evident for many families, since the custody implies an emotional and educational investment, which is not simple to manage: Since adolescents-most of them foreigners - are involved, it is necessary to negotiate rules and to have the ability to let them go when they are autonomous.

It would be appropriate from the one part to protect the families involved from stress, from overload, from the breaking of the equilibrium, and from an exaggerated emotional investment. From the other part, the realization of a training path directed to families interested in fostering would be useful for facilitating a good match between the minor and the family.

\section{CONCLUSIONS}

Ministry of Labour and Social Policy's guidelines Linee di Indirizzo per L'affidamento Familiare (2013) support and foster the spreading and start-up of unaccompanied foreign minors' family fostering as one of the preferred instruments of intervention, of support and control of this phenomenon, foreseeing the involvement of public administrations and their active role in defining operational procedures [Ministero del Lavoro e Delle Politiche Sociali (Ministry of Labour and Social Policy) 2013: 56-58].

Even the Parliamentary Committee on Childhood and Adolescence proposes and recommends family 
fostering as an effective instrument for unaccompanied foreign minors. Quoting the report Indagine Conoscitiva sui Minori Stranieri non Accompagnati approved by the Committee in 2012: "The fact that many families fostering minors (as indicated to the Committee) would be available for fostering unaccompanied foreign minors conveys the opportunity that the authorities responsible for the management of unaccompanied foreign minors take into consideration different integration paths from the ones foreseen by the actual law" [Italia. Commissione Parlamentare per L'infanzia e L'adolescenza (Italy. The Parliamentary Commission for Childhood and Adolescence) 2012: 19].

Although the needs stated by the youngster are, in most of cases, material ones, actually he needs to be listened and recognized by the hosting community, which has to be open to the diversity, to the dialogue, to the encounter (Arnosti 2008: 125), and to the social inclusion of all the subjects living locally. Family is an integral part of the social community and has a relevant social role.

The family is an appropriate environment for growing healthy and coherently, respecting natural rhythms. Fostering a minor in a stimulating family environment allows a circumstantial social, educational, and professional integration; it offers to the adolescents an emotional environment for overcoming the loneliness and the social isolation deriving from the arrival in a new and unknown context. The family can offer a place where to think about themselves, adults are stable referents and the functioning of the family is more inclusive than the one characterizing residential community. The family offers greater guarantees about the future and continues to be a reference point after the legal age, since relationships and bonds will last.

Family foster care is a complex instrument that can be a positive experience for the minor and for the family; it has to be promoted in the civil society by training the families to let them meet it.
This has to be taken into account without simplistic analysis and without minimizing the critical issues on fostering and on failures that can happen in the helping processes.

Family fostering is a valiant alternative allowing to differentiate the interventions and to direct social services toward different resources and opportunities, making use of the community resources, especially time and energies of fostering families and their associations. By enhancing the diversification of the interventions, it is possible to leave welfare dependency that could be a risk, and it is possible to enforce community and solidarity values.

If realized in a correct manner, family fostering allows the implementation of the collaboration between public administration and formal and informal groups, (is) precious for increasing the opportunities for the minors.

\section{References}

Arnosti, C. 2008. Strategie per L'accoglienza. L'affidamento Omoculturale di Bambini e Ragazzi in Emilia Romagna (Strategies for the Reception. Omo-Cultural Custody of Children and Teenagers in Emilia Romagna). Retrieved (http://sociale.regione.emilia-romagna.it/documentazione/ pubblicazioni/guide/quaderni-del-servizio-politiche-familia ri-infanzia-e-adolescenza/17.-strategie-per-12019accoglienz a).

Arnosti, C. and F. Milano. 2006. Affido Senza Frontiere. L'affido Familiare Dell'adolescente Straniero non Accompagnato (Foster Care Without Borders. The Foster Care for Unaccompanied Foreign Teenager). Milano: Franco Angeli.

Cittalia, A. 2012. IV Rapporto-I Minori Stranieri non Accompagnati in Italia (IV Report-The Unaccompanied Foreign Minors in Italy). Retrieved (http://I_Minori_Stranieri_2012-iv_rapp.pdf).

Di Nuzzo, A. 2013. Fuori di Casa. Migrazioni di Minori non Accompagnati (Outside Home. Migrations of Unaccompanied Minors). Roma: Carocci Editore.

Donati, P., F. Folgheraiter, and M. L. Ranieri. 2011. La Tutela dei Minori: Nuovi Scenari Relazionali (Child Protection: New Relational Scenarios). Trento: Erickson.

Gandini, M. 2007. Dentro un Camion. Voci Dall'italia e Dalla Grecia di Minori Afgani Separati (Inside a Truck. Voices 
From Italy and Greece of Afghan Minors Separated). Torino, Italia: L'Harmattan.

Italia. Commissione Parlamentare per L'infanzia e L'adolescenza (Italy. The Parliamentary Commission for Childhood and Adolescence). 2012. Indagine Conoscitiva sui Minori Stranieri non Accompagnati. Documento Conclusivo Approvato Dalla Commissione il 27 Marzo 2012 (Public Consultation on Unaccompanied Foreign Minors. Closing Document Approved by the Commission on March 27, 2012). S.I.: s.n.

Ministero del Lavoro e Delle Politiche Sociali (Ministry of Labour and Social Policy). 2013. Linee di Indirizzo per L'affidamento Familiare (Guidelines for Foster Care). Retrieved (http://www.minori.it/sites/default/files/linee_ guida_affidamento_familiare_2013.pdf).

-2011. Affidamenti Familiari e Collocamenti in Comunità al 31/12/2011 (Family Foster Care and Community Placements up to 12/31/2011). Retrieved (http://www.lavoro.gov.it/Strumenti/StudiStatistiche/sociale
/Documents/qrs26_affido.pdf).

- 2015. Report Nazionale. Minori Stranieri non Accompagnati; Aggiornato al 30 Novembre 2015 (National Report. Unaccompanied Foreign Minors; Updated as of November 30, 2015). Retrieved (http://www.lavoro.gov.it/ AreaSociale/Immigrazione/minori_stranieri/Documents/Re port\%20MSNA\%2030-11-2015.pdf).

Salimbeni, O. 2011. Storie Minori. Realtà ed Accoglienza per $i$ Minori Stranieri in Italia (Minor Stories. Reality and Reception for Foreign Minors in Italy). Pisa: Edizioni ETS.

Vari, A. 2009. L'affido Omoculturale in Italia (Omo-Cultural Foster Care in Italy). Roma: Sinnos.

\section{Bio}

Anna D'Andrea, master's degree in work, social citizenship, interculturality, Università Ca' Foscari di Venezia, Italy; research field: sociological disciplines. 